http://jmscr.igmpublication.org/home/ ISSN (e)-2347-176x ISSN (p) 2455-0450 crossref DOI: https://dx.doi.org/10.18535/jmscr/v8i1.132

Journal Of Medical Science And Clinical Research

\title{
Abruptio Placenta - A Study in Tertiary Care Centre
}

\author{
Authors \\ Dr K. Abirami M.S. OG*, Dr A. Narmadhapriya MS OG PG \\ *Corresponding Author \\ Dr K.Abirami M.S. OG \\ Assistant Professor, Dept of Obstetrics and Gynaecology, GRH Madurai, India
}

\begin{abstract}
Introduction: Separation of the normally situated placenta either partially or totally from its implantation site before delivery is described as abruptio placentae. It is one of important cause for antepartum haemorrhage. The phenomenon of impaired trophoblastic invasion with subsequent atherosis is related in some cases of preeclampsia and abruption. Inflammation or infection may be contributory. Inflammation to be more common in prematurely separated placentas.

Aim: The aim of the study is to find the incidence of abruption in a tertiary care centre, its risk factors and to monitor maternal and fetal outcome

Material \& Method: This is prospective observational study. The study was conducted at Madurai Rajaji hospital, over 3 months from June to august .total number of deliveries for 3 months being 3870 , of which we had 25 cases of abruption. All the women who were admitted with bleeding pv and preterm labour was taken as the study population.

Result: The incidence of abruption was $0.6 \%$ which is statistically significant and is similar to other studies. The incidence is $36 \%$ among the age group 20 to 25. The incidence $40 \%$ more among multigravida. $60 \%$ mothers presented with pain abdomen and abnormal FHR at the time of admission. Almost $64 \%$ of the mothers had Non severe preeclampsia which was the important risk factor associated with abruption the other risk factor were anemia, multiple pregnancy, preterm labour and prevlscs. Concealed abruption was seen in $68 \%$ of the cases. $90 \%$ of the mother were delivered by emergency caesarean section. $60 \%$ of the mother required blood transfusion. Fetal mortality was seen in $68 \%$ of cases. Maternal morbidity was more. DIC was the most common complication. 3 patients went in for acute renal failure requiring dialysis. 2 pts developed pulmonary edema. Maternal mortality with abruption was Nil at our centre.

Conclusion: Abrutio placenta is one of the obstetric emergency which results in maternal morbidity and fetal mortality. A timely referral, early identification of risk factors, early diagnosis, can improve the maternal outcome and fetal outcome.

Keywords: Abruption, non severe pre eclampsia, blood transfusion.
\end{abstract}

\section{Introduction}

Separation of the normally situated placenta either partially or totally from its implantation site before delivery is described as abruptio placentae. It is one of important cause for antepartum haemorrhage. The phenomenon of impaired trophoblastic invasion with subsequent atherosis is related in some cases of preeclampsia and abruption. Inflammation or infection may be contributory. Inflammation to be more common in prematurely separated placentas. 
Placental abruption is due to rupture of uterine spiral artery. Bleeding into deciduas leads to separation of placenta. Hematoma formation further separates the placenta from the uterine wall causing compromise of the blood supply to the foetus. The types are-A-Revealed-blood tracks between the membranes and escapes through the vagina and cervix. B- Concealed blood collects behind the placenta with no evidence of vaginal bleeding.

The classification of placental abruption is based on the following clinical findings:

Class 0: Asymptomatic

Discovery of a blood clot on the maternal side of a delivered placenta

Diagnosis is made retrospectively

Class 1: Mild

No sign of vaginal bleeding or a small amount of vaginal bleeding.

Slight uterine tenderness, Maternal blood pressure and heart rate $\mathrm{WNL}$

No signs of fetal distress

Class 2: Moderate

No sign of vaginal bleeding to moderate amount of vaginal bleeding

Significant uterine tenderness with tetanic contractions

Change in vital signs: maternal tachycardia, orthostatic changes in blood pressure.

Evidence of fetal distress. Clotting profile alteration: hypofibrinogenemia

Class 3: Severe

No sign of vaginal bleeding to heavy vaginal bleeding, Tetanic uterus/ board-like consistency on palpation, Maternal shock Clotting profile alteration: hypofibrinogenemia and coagulopathy. Fetal death.

Classification of 0 or 1 is usually associated with a partial, marginal separation; whereas, classification of 2 or 3 is associated with a complete or central separation.

It is a serious obstetric condition that increases maternal and neonatal morbidity and mortality. Most of our cases had concealed haemorrhage
Abruption occurs in $0.4-1 \%$ of pregnancies. Obstetric haemorrhage accounts for $1 / 3$ rd of maternal death. Perinatal mortality is high with abruption due to its strong association with preterm. Even babies born at 40weeks of gestation, birth weight of $3.5-3.9 \mathrm{~kg}$ had 25 -fold higher mortality with abruption. The main precipitating and predisposing factors of abruption are age, parity, anemia, poor nutrition, pregnancy induced hypertension, eclampsia, gestational diabetes mellitus, \& premature rupture of membrane.

Abruption is a significant cause of maternal and perinatal morbidity and mortality.. Abruptio placenta is the major cause of haemorrhagic shock, DIC, renal failure, ischemic necrosis of organs in the mother. Fetal complications include hypoxia, anemia, growth restriction, prematurity, neurodevelopmental problems and premature death. Hypertensive disorder of pregnancy is associated with $2.5 \%$ to $17.9 \%$ of placental separation. And the relationship was significantly higher in our studies.

\section{Material \& Method}

This is prospective observational study. The study was conducted at Madurai Rajaji hospital, over 3 months from June to august. Total number of deliveries for 3 months being 3870 , of which we had 25 cases of abruption All the women who were admitted with abdomen pain, bleeding per vaginum after 28 weeks of gestation was taken as the study population .From those case records, details regarding the age of the patient, parity and maternal high-risk factors were collected. All other causes of APH like placenta previa and other extra placental causes were excluded. All study patients underwent a complete obstetrical examination and clinical workup including history, general physical examination and abdominal and pelvic examination. And emergency ultrasound in stable cases Detailed obstetric history was obtained and maternal highrisk factors like PIH, GDM, polyhydramnios was noted. As $95 \%$ patients were admitted as 


\section{JMSCR VoI||08||Issue||01||Page 816-821||January}

emergencies, placental abruption was suspected depending on clinical features of vaginal bleeding, uterine tenderness, hypertonic uterus and diagnosis was confirmed by retro placental clots post delivery.

Fetal wellbeing was assessed by cardio tocography. Patients were managed according to the fetal and maternal conditions. Primary outcome of the study was to obtain the incidence of abruption inactivated tertiary care hospital. Secondary outcome being Maternal complications that was encountered were PPH, DIC, ARF and pulmonary edema and Foetal outcome in the form of perinatal mortality (still births and neonatal deaths), prematurity and admission to the neonatal care unit were also studied.

\section{Results}

The incidence of abruption was $0.6 \%$ which is statistically significant and is similar to other studies $^{(1)}$

Age

\begin{tabular}{|l|c|c|c|c|c|}
\hline Age & 15 to 20 & 20 to 25 & 25 to 30 & 30 to 35 & $>35$ \\
\hline Number & 4 & 9 & 6 & 4 & 2 \\
\hline percentage & $16 \%$ & $36 \%$ & $24 \%$ & $16 \%$ & $8 \%$ \\
\hline
\end{tabular}

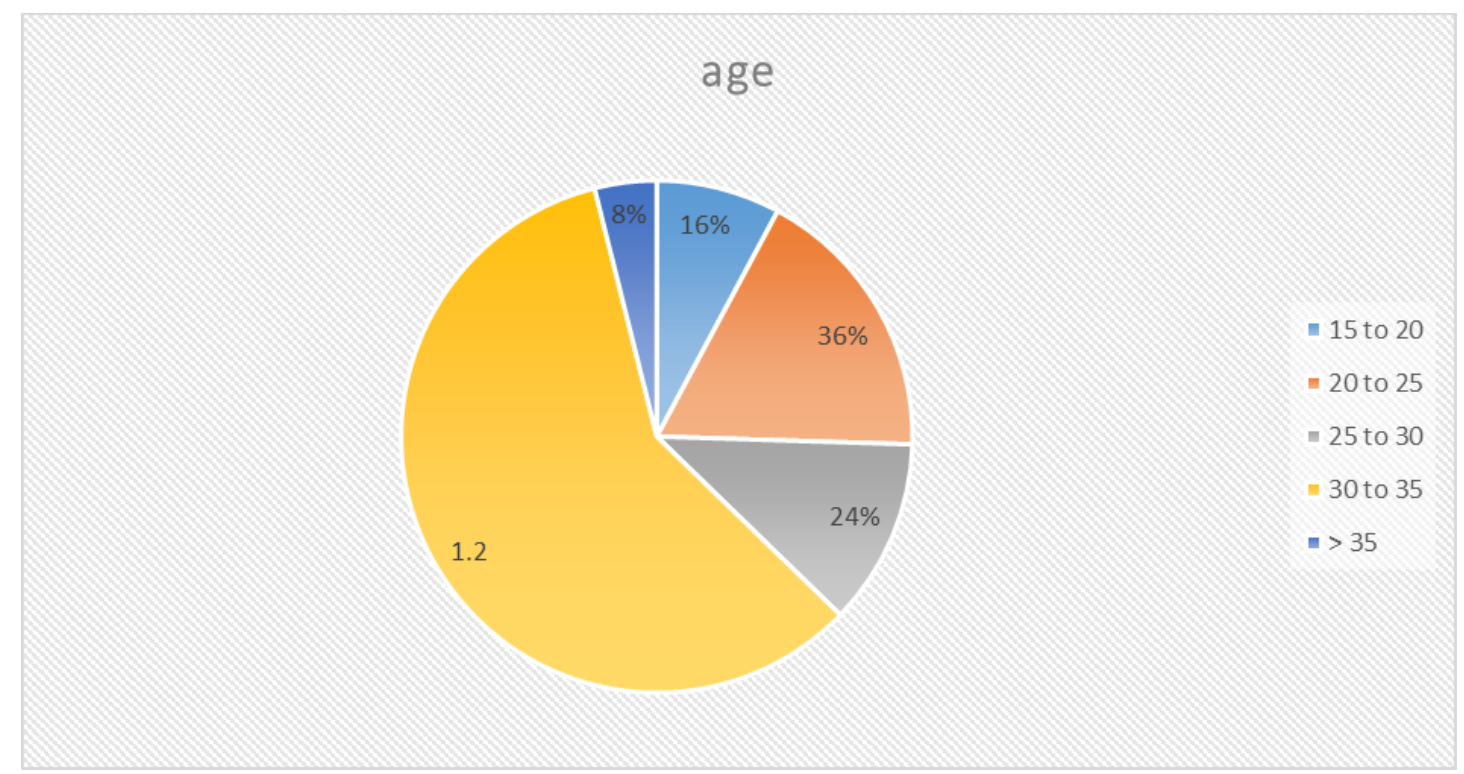

Fig 1: Incidence of abruption among different age groups

Incidence of abruption is more common in age group 20 to 25 years of age it is around $36 \%$, the incidence was $24 \%$ between 30 to 35 years of age this is similar to other studies. ${ }^{(1)(4)}$

\section{Parity}

Table 1: Incidence of abruption according to parity

\begin{tabular}{|l|c|c|}
\hline Primi & 6 & $24 \%$ \\
\hline G2P1L1 & 7 & $28 \%$ \\
\hline G3P2L2 or more & 10 & $40 \%$ \\
\hline
\end{tabular}

The incidence of abruption increases with increasing parity. This is similar to study ${ }^{(1,2)(12)(13)(14)(15)}$ 


\section{Symptoms}

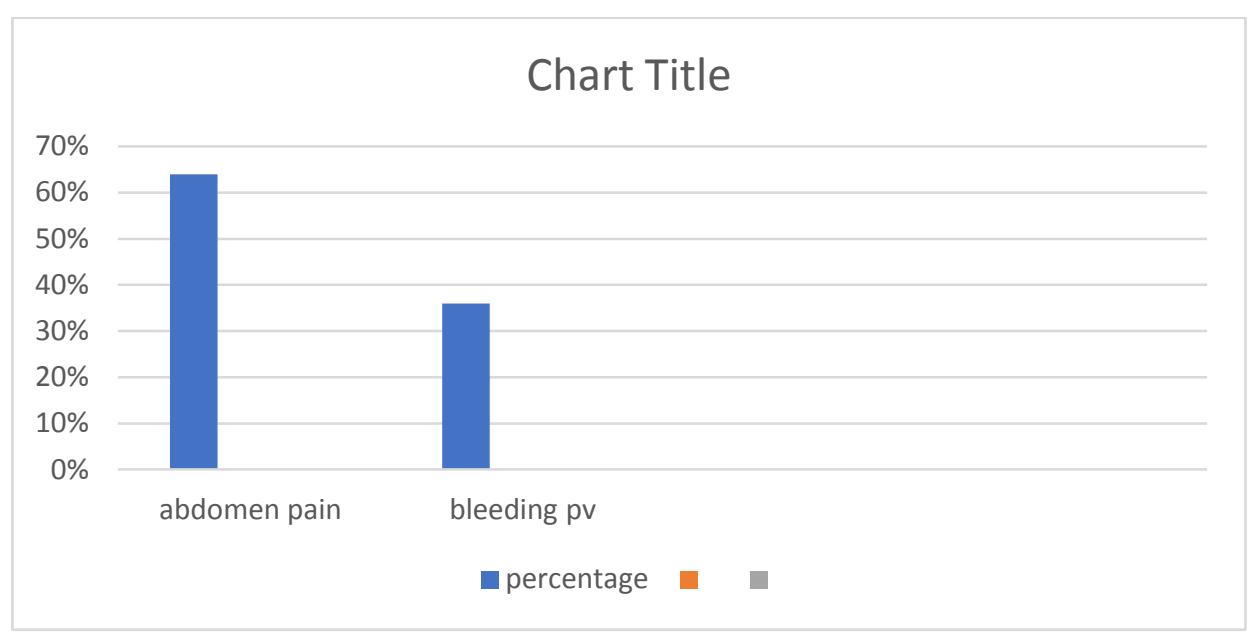

Fig 2: Presenting Symptom

The most common presenting symptom was abdominal pain which was seen in $64 \%$ of cases admitted with abruption. $36 \%$ presented with bleeding per vaginum associated with hypertonic uterine contractions. $^{(4)(5)}$

\section{Risk factors}

\section{risk factors}

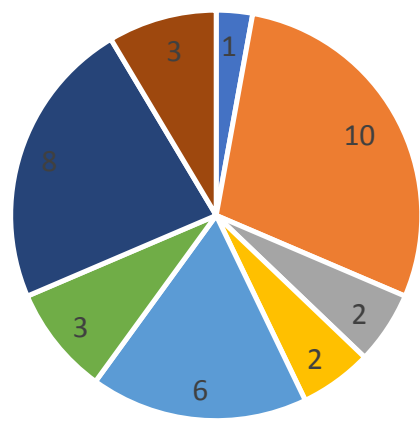

$$
\begin{array}{ll}
\text { - chronic hypertension } & \text { - non severe preeclampsia } \text { - severe pre eclampsia } \\
\text { m eclampsia } & \text { - prev Iscs } \\
\text { - preterm labour } & \text { - multiple pregnancy }
\end{array}
$$

Fig 3: Risk factors associated with abruption

The most common risk factor for abruption was preeclampsia it was found in $60 \%$ of cases $^{(3)(5)(6)}$. $12 \%$ patient had anaemia, preterm labour was seen in $32 \%$ of cases and $12 \%$ in multiple pregnancy. prevlscs was seen in $24 \%$ of cases More than $70 \%$ cases presented with abnormal Fetal heart Rate or absent Fetal heart rate so $99 \%$ of the cases was taken for emergency lscs only one percent had normal delivery $68 \%$ of cases had no retroplacental clot in USG, proving that is abruption is not a ultrasound diagnosis, its purely a clinical diagnosis. $32 \%$ had reteoplacental clot in ultrasound.

$60 \%$ of cases were concealed abruption. $68 \%$ fetal outcome was guarded, and 60\% maternal morbidity. there was no maternal mortality with abruption in our institute. 


\section{Complications}

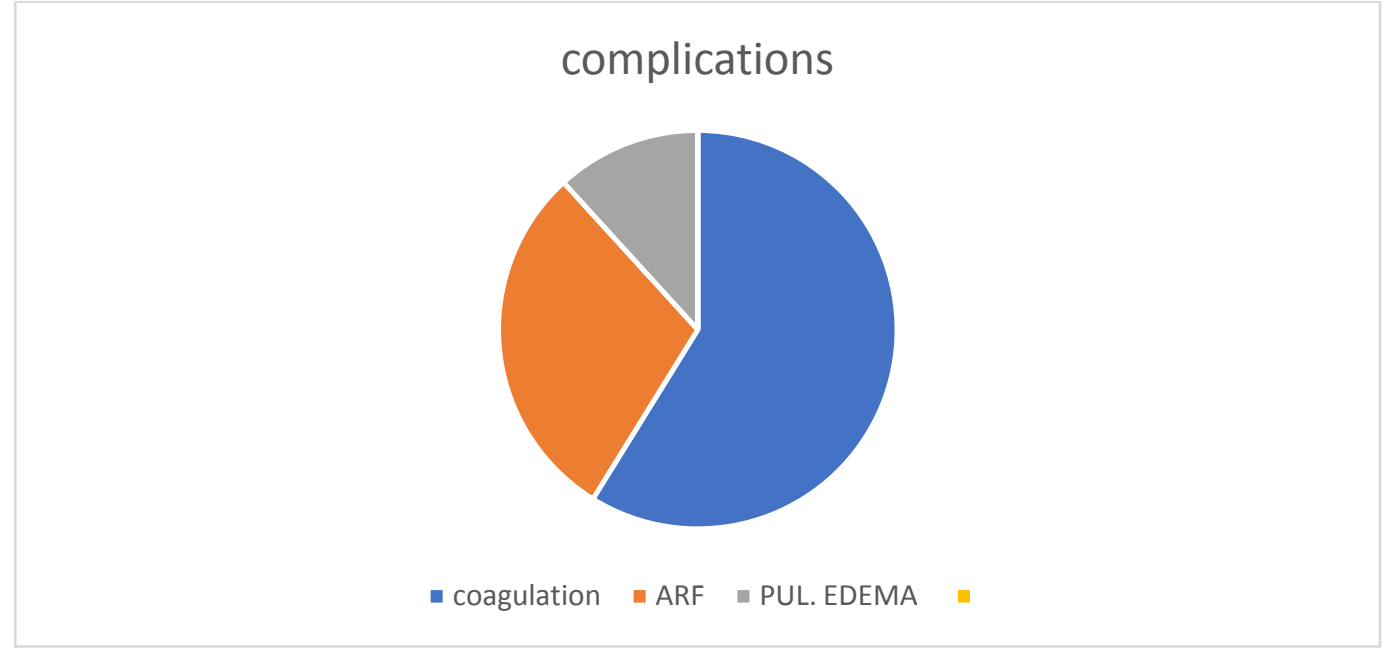

Fig: 4 Maternal complications following abruption

Most of the mothers required blood transfusion. 3 mothers ended up in ARF needing dialysis. 3 mothers had all 3 complications DIC, ARF and acute pulmonary edema.

The perinatal mortality was high with those babies born to mothers who had abruption, it was $68 \%$ in our study, this is because our centre being the referral centre we had most of cases with severe fetal bradycardia or intra uterine demise following abruption among these $52 \%$ presented as fresh Intrauterine death following abruption. $26 \%$ were admitted in NICU in view of prematurity, fetal distress following abruption. $6 \%$ were live birth babies were born without any complications. ${ }^{(12)(15)}$

\section{Discussion}

Placental abruption is a serious and often lifethreatening condition to the fetus and, to a lesser extent, to the mother. The incidence of abruption is $0.6 \%$ which is similar to other studies like alka $\&$ kavitha et al, where the incidence of abruption was $0.9 \%$, the overall global incidence of abruption is 0.5 to $1 \%$. The signs and symptoms of abruptio placenta vary depending upon the severity of bleeding and the degree of separation of the placenta. Abruption can occur at any stage in pregnancy but 32-36 weeks appears to be the most vulnerable time of gestation. 25 cases of abruption placentae were present out of 3870 deliveries at GRH, MADURAI between July to
September $36 \%$ of patients lying in the age group of 21 to 25 yrs. About $50 \%$ were multiparous with no formal education rest of the mothers belonged to low socioeconomicststus, few women were hard working labourers. $32 \%$ pregnancies culminated as preterm between 33 to 36 weeks. Out of the various risk factors associated with abruption placentae, the ones that had profound influence this study turned out to be

- Multigravidity and multiparity, $40 \%{ }^{(1)}$

- Pregnancy induced hypertension and preeclampsia,64\%. ${ }^{(6) ;(12)(13)}$

In our study the perinatal mortality was quite high compared to other studies as our centre being referral centre we received cases of abruption in late stage or few cases were grade 3 abruption. ${ }^{(5)}$ Proper AN care and early identification of risk factors with prompt referral of cases of APH can reduce the number perinatal mortality and can bring down the maternal morbidity .

\section{Conclusion}

Abruptio placenta is one of the obstetric emergency which results in maternal morbidity and fetal mortality. A timely referral, early identification of risk factors, early diagnosis, can improve the maternal outcome and fetal outcome. 


\section{References}

1. An observational study of feto-maternal outcome in cases of abruptio placentae Alka*, Kavita Dudhrejia A longitudinal study of incidence and pregnancy outcome of abruption placenta at the-tertiary hospital in Gambia Volume 5 Issue 2 2019

2. Matthew Anyanwu,1,2 Claudette Amuzu, Mustapha bittaye, Patrick Idoko

3. Ananth CV, Lavery JA, Vintzileos AM. Severe Placental Abruption:Clinical definition and associations with maternal complications. Am JMObstetGynaecol. 2016;214;272.e1-9

4. Willium A, Lieberman E, Mittendorf R. Risk factors of abruption placentae. A J of Epidemiol. 1991; 134(9):965-72.

5. Wasnik SN and Naiknaware SV. Antepartum Haemorrhage: Causes and its effects on Mother Child: An Evaluation. Obstetri Gynaecol Internat J. 2015;3 (1):00072.

6. Bibi S, Ghaffer S, Pir MA, Yousfani S. Risk factorsVand clinical outcome in placental abruption: aVretrospective analysis $\mathrm{J}$ Pak Medic Associat. 2009:59(10):672-4.

7. Talpur NN, Memon SR, Jamro B, Korejo R. Maternal and fetal morbidity with abruptio placentae. Rawal Med J. 2011;36(4):297-300.

8. Sher G. Pathogenesis and management of uterine inertia complicating abruptio placentae with consumption coagulopathy. Am J Obstet Gynecol.1977;129:164-70.1

9. Campbell S, Lee C. Disorders of placentation. In: Obstetrics by ten teacher 17th ed. Arnold London 2002.p.171-3.
10. Shrivastava V, Kotur P, Jauhari A. Maternal and Fetal outcome among Abruptio Placentae at a rural tertiary hospital in Karnataka, India: A Retrospective analysis. Int J Res Med Sci. 2014;2(4):1655-8.

11. Bener A, Saleh NM, Yousafzai MT. Prevalence and associated risk factors of ante-partum hemorrhage age among Arab women in an economically fast growing society. Niger J ClinPract. 2012;15:1859.[PubMed] [Google Scholar]

12. Zamani E. Kerman, Iran: School of Medicine, Kerman University of Medical Sciences; 2009. Study of the frequency of obstetrical antepartum hemorrhage and the causes among pregnant patients at tending the center of Afzalipoor Hospital, Kerman. $\mathrm{PhD}$ Thesis. [Faroo

13. Abbasi RM, Rizwan N, Mumtaz F, Farooq S. Maternal outcome among abruption placentae cases at a University Hospital of Sindh. JLUMHS. 2008;7:106-9.[Google Scholar]

14. Ananth CV, Smulian JC, Demissie K, Vintzileos AM, Knuppel RA. Placental abruption among single to and twin births in the United States: Risk factor profiles. Am J Epidemiol. 2001;153:771-8. [PubMed

15. Budde MP, DeLange TE, Dekker GA, Chan A, Nguyen AM. Risk factors for placental abruption in a socioeconomically disadvantaged region. $\mathrm{J}$ MaternFetal Neonatal Med. 2007;20:68793. [PubMed] [Google Scholar]. 